\title{
Towards Understanding Design Expertise as a Developmental Dynamic: A Learner's Perspective
}

\author{
Tanja Golja, University of Technology, Sydney, NSW, Australia \\ Lynette Schaverien, University of Technology, Sydney, NSW, Australia
}

\begin{abstract}
The capability to design, and thereby shape a culture's ascent over time, might well be one of the most basic characteristics of what it is to be human. Cultures value successful designs; hence the urgency of understanding the principles and practices that underpin design success. One approach to gaining insights into design has been through exploring the processes of proficient, experienced designers, often in comparison with those of novices. However, researchers are beginning to question the worth of such investigations, arguing that they tell proficient designers little more about design than what they already know from their practice. Nor do they give an account of how these so-called experts might develop their design practice over time in response to emerging needs, pressures or opportunities, for example, so as to design sustainably, in circumstances of resource shortage or with new technologies. Moreover, such studies risk a far too stark and static a priori dichotomy between novice and expert, simply on the basis of their experience at a point in time, suggesting the need to look more closely at how people might develop their design capability. This paper reports preliminary findings of the first part of a doctoral study by a learner-as-researcher, who sought insights into the nature of design by documenting her own developing learning to design over a university semester in an undergraduate architectural design class. Here, we give a brief account of the first phase of her learning to design as a participating member of this class community. We describe some of the design ideas she generated, her early perceptions of designing in this context and some actions she subsequently took, alongside the developing ideas of other students and in response to teacher critique. We speculate on the power of this approach to understanding designing, including how it might inform the teaching of design and the creation of environments conducive to designing.
\end{abstract}

Keywords: Learning to Design, Design Expertise, Undergraduate Architecture, Teaching Design

\section{Introduction}

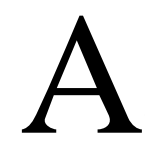

CENTRAL CHALLENGE for design education is how to grow expertise. The depth of this challenge is clear in Cross' (2004) words,

Education in design has well-established practices that are assumed to help progression from novice to expert; but there is still precious little real understanding of the differences between novice and expert performance in design, and how to help students move from one to the other (p. 429).

Such a statement appears paradoxical: on what basis might practices in design education be well-established, if data about differences between experts and novices is being found wanting and if we are as yet so unclear about the developmental dynamic of moving from novice to expert?

There has been a passing parade of dominant paradigms in terms of which educators have sought to understand expertise (Feltovich, Prietula \& Anders Ericsson, 2006). Behaviourists described how learners refine their design repertoires by way of feedback, establishing particular, well-defined behaviours which are taken as evidence of superior performance. Cognitive psychologists defined novice cognition as 'initial states' - educational starting points - and expertise as a goal state; in such a scenario, educational processes became 'a sort of means-ends analysis, [in which the task] was to determine the kinds of operations that could transform the initial conditions into the desired more expertlike ones' (after Glaser, cited in Feltovich et al, 2006, p. 45-6). Information processing studies characterised expertise as displaying visible evidences of proficiency in problem solving. However, with their strong dependence on well defined end-states-inview, such conceptions did not address how expert behaviours might shift and change in cultures, in unanticipated ways, over even longer time spans (for example, decades or centuries). Such neglect in accounting for the evolution of design ideas within architecture constitutes a serious problem if it is to be understood as a research-based profession.

According to Chi (2006), studies of expertise are of two kinds. On one hand, absolute approaches study exceptional performance to distil those criteria that constitute expertise. Relative approaches, on the other hand, compare and contrast expert and novice 
practices on set tasks over time, so as to develop a continuum of descriptions of more to less knowledgeable designing practice. Studies of the development of design expertise do not always fall easily into these categories, however (for example, Atman et al, 1999; Kavakli and Gero, 2002; SeitamaaHakkarainen and Hakkaraninen, 2001; Eteläpelto, 2000); and analysis of these approaches provoke critique on a number of fronts. For example:

- When, exactly, does a novice become an expert? Might there be gradual growth (for example, on a scale such as Hoffman's proficiency scale (1998) adapted by Chi (2006, p. 22)) rather than there simply being a bipolar divide or even a threshold point?

- Much research about developing expertise is conducted in strictly circumscribed contexts such as chess games, making extrapolation of its findings to the learning of other much more elaborate and less precisely specified cultural practices problematic (Ross, 2006).

- At least some of the research techniques (such as think aloud protocols) might well disturb or alter the phenomenon under study. Worse still, with too fixed a view of expertise as an educational end and a similarly fixed idea of design education as a means towards that end, individual differences between learners as they grow their expertise risk being lost as noise; and an oversimplified account of common development risks being written.

For these reasons, we argue the need for an empirical study of design expertise of a different and complementary kind: a fine-grained study of how one learner begins to develop expertise in architectural design. Furthermore, if a particular design context (for example, introductory architectural design) can be well understood, then inroads can be made into explaining the development of design expertise more broadly. So, in this first study from a two-part doctoral investigation, insights into architectural designing will be distilled thereby refining an understanding of the concept and/or process of design. The present paper describes and analyses the data from the first four weeks of the first study. Rather than considering this account in terms of a progression towards prefigured ends, we will examine it for developmental evidence of learning.

\section{Research Design}

TG, the first author, a doctoral student (whose supervisor is the second author, LS), participated as an undergraduate student in the introductory subject entitled Architectural Design: Design Basics in the Faculty of Design, Architecture and Building of her university. Taking such a step enabled her to learn how to design in those most conventional ways of the higher education sector in which she finds herself: thereby becoming a learner-as-researcher. Formal consent from students, the teaching academic, the tutors, and the faculty was sought and obtained through the university's Human Research Ethics Committee before the study could begin. Once the study had been formally approved, and within the normal course of the subject, TG was able to develop her ideas about architectural design alongside other learners doing the same; and she could avail herself of the teaching academic's professional views of design and feedback on her developing ideas as well as those of the tutors (who were practicing architects). By growing her concept of architectural design as a learner-as-researcher, TG was hedging the chances that she would understand, more deeply, the psychological dimensions of designing rather than only its logical or disciplinary dimensions.

Thus, this empirical study was an autobiographical one (Lancy, 1993): a bounded case study (Stake, 1995; Merriam, 1998). In essence, TG documented her learning to design in this architectural design subject as follows:

- She attended all the lectures and studios over the thirteen-week semester, and undertook all the requirements of the subject including submission of the three assessment tasks.

- She used the subject documentation such as subject outline, handouts and PowerPoint slides from the lectures.

- She kept extensive chronological fieldnotes of her own thoughts, questions, sketches and models as they occurred and in such a way as not to disrupt the designing itself.

- She kept all the design artefacts she made, taking digital photographs of them.

- She audiotaped lectures and studios (after Week One) using a digital audio recorder, as unobtrusively as possible, for subsequent review. She did not audiotape the first week's lecture and studio, preferring more gradual steps towards developing the means of recording her learning in this class community. Instead, she took extensive notes during these initial sessions, and made fieldnotes of her own thinking at the time.

- She took selective video recordings during the studio starting in Week Three, when and if she felt it might help her own learning. She mostly rested the video recorder on her desk and it became obvious that its presence soon went unnoticed. No video recording was made in Weeks One and Two so that students and the tutors might perceive her presence as primarily that of a learner in the class. 
At the end of the semester, once the subject results had been finalised, TG participated in four individual conversations with students (ranging from 60 minutes to two hours) to test out her ideas about design by hearing other students' first person accounts of their designing during the semester. Likewise, and soon after, she had a sustained conversation with the teaching academic of the subject. Furthermore, once she began to analyse her data, TG tried to situate her experiences of designing within what she understood of the broad and deep literature of this field.

Our paper reports on the first phase (the first four weeks) of TG's learning. A lecture and a studio session were the key teaching events each week for the approximately 85 students enrolled in the subject. All were scheduled to attend the one-hour lecture, at twelve on Fridays in a small lecture theatre. This was followed by a half hour lunch break and then a three-hour studio (from 1:30-4:30 pm) with students allocated to one of five studio groups. The studio class was held in a room with large movable work desks and pin boards. Each tutor rotated between studios over the semester to act as client or design critic to other studio groups. In the case of TG's studio class, her tutor was also the teaching academic who gave the lectures and co-ordinated the subject.

\section{An Account of Learning to Design: First Four Weeks}

We use the following set of figures to give a compressed, chronological account of the first four weeks. Beginning with the first week of the teaching semester, students were introduced to the nature of the subject Architectural Design: Design Basics and they started to work on the studio design project (see Figure 1). In Week Two there were three interwoven threads: thinking about how buildings come to be the way they are, meeting the client to get a design brief for her building (a weekender), and generating three design ideas based on this brief (see Figure 2). Then, the third week's lecture focused on how previous first year architecture students perceived 'design' and in the studio students presented their three initial design ideas to the class and received tutor feedback (see Figures 3 and 4). The final week in this account covers how students progressed the two selected ideas with the tutor's assistance in preparation for the following week's meeting with the client to show her their proposals for her weekender (see Figures 5, 6 and 7). Each of these weeks' events is located on a vertical timeline: starting with a short description of the lecture and studio session (including excerpts from subject materials), this is followed by a first person summary of what TG did as a learner (what she thought about, questions, ideas and con- cepts that emerged during the week after the lecture and studio and how she represented them to herself and to others over the course of her study in the class community).

\section{Discussion}

We began this paper with the realisation that the developmental dynamic of moving from novice designer to expert is not well understood, potentially questioning the strength of the foundations of established practice in design education. Even more worryingly, we intimated that some research approaches to investigating the development of design expertise may risk disturbing the ways it might occur and/or deliver oversimplified accounts, provoking us to undertake this researcher-as-learner study in a particular designing context: architecture education. Having reported these early weeks' data, we now discuss its educational import.

In Weeks One and Two of this design project, and with little experience or knowledge of the field of architectural design, TG worked to broaden, enrich and support the supply and emergence of a rich, fluid source of ideas from which a design form might take shape. So, for example, she purchased architecture magazines ('glossies') and browsed through them to collect ideas that seemed to be in tune with the client's brief or that she found to be intriguing in light of the design project; and she tinkered with materials she could use for modelling to assist her to generate a wealth of ideas. Some early emerging ideas (such as rooms that curved around an internal bush courtyard) remained salient. Others (such as an unsheltered first storey balcony amongst the treetops) did not. Ideas were generated and culled as they interacted with aspects known to TG and which became known during the first two weeks of the semester: factors such as the environment around the site location, the site particularities, the specific climatic conditions where the site itself was located, functions of a particular type of building (a weekender) and the cultural practices that occur in such a building. Of course, TG's own subjective and personal experiences and knowledge filtered her design ideas, as did details of the client's brief (for example, the unique beauty of the Australian bush site itself with its spectacular views of cliff faces and along a valley, TG's own experience of living in this Blue Mountains area, and the client's desire to situate a weekend writing retreat which brought the spectacular and peaceful nature of the location into the building itself). TG worked to represent these initial ideas through descriptive text, through sketches and drawings, and through models using a particular moulding material. 


Lecture: The teaching academic gave students a detailed description of the subject's work, comprehensive
subject handouts, and he raised many questions; for example. What does it meon to soy thot you hove designed
something? Whot does it mean to soy that orchitecture embodies ideos? Are 'ideos' the same os 'concepts? The
subject used a project - to design a small building (an innovative and spectacular weekender) for a particular client
- as a means by which to introduce students to 'the conceptual and imaginative process in architectural designing
and to architecture as an embodiment of ideas' (Subject Outline, 2005, p. I).

Particular expectations were raised in the lecture and studio sessions:

'Designing a house ... both its scale and its nature make it a building type that faciltates adventurous form-making and experimentation.

The client expects ... not just a building that meets their requirements although they certainly do expect this - but a really striking piece of architecture; something that speaks of design; that is visually strong that stands out in a form and compositional sense; that offers a desirable and stimulating living experience; that will be recognized (at least in architectural circles); and that might win awards and hit the glossies'.

The tutors expect the design outcomes of students in this studio to provide for an appropriate and satisfactory meeting of the requirements of the brief in a manner that provides an exciting and dynamic spatial form.' (Project Outline)

\section{Studio:}

$1.30-2.15$ The studio design project was introduced and detailed in a handout.

$2.15-3.00$ The tutor worked with students to develop a generic pre-brief which consisted of a list of requirements for a house (a weekender).

$3.00-3.30$ Students were issued with a generic brief of what might be expected in a weekender.

$3.30-4.30$ The site was discussed and analysed. Students were given a site map and were shown images of the location to highight its stunning features: to the north east were enormous orange rock faces: mist and fog rolled through the north west valley; the site was situated in eucalypt bush.

During the week, students were to undertake a spatial and functional analysis of a generic house, and to explore the size and spatial requirements of common objects in such a house.

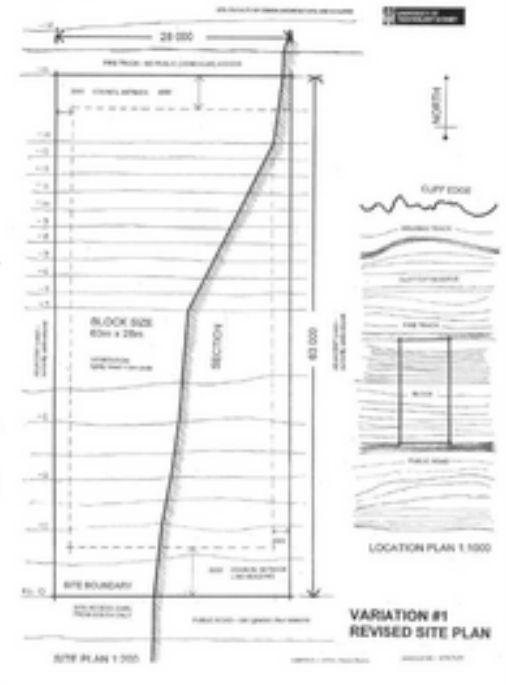

Site Plan

Developing ideas: This first week's lecture and studio generated a rich set of ideas over the succeeding days. TG:

- Asked: What is a concept and how is it different to an idea?

- Explored: What is a concept? by looking through various books.

- Found: Mayr (1998) 'changes in concepts have far more impact than new discoveries' (p. 98).

- Asked: So are concepts the components of a particular woy of carving up the world? Are they the perceptual categonies?

- Reminisced: about buildings that she had previously lived in as home.

- Observed: features of her current home (windows, proportions, what things looked out onto).

- Found and browsed: some home glossies on a pile of magazines at her home.

- Searched: the Internet for the dimensions of different bed sizes.

- Recorded: the sizes of different bed types.

- Measured: her own bed.

- Made: a grid paper model of her current bedroom to scale I:100.

- Measured: the size of different rooms at her home (including celing height).

- Developed: a sense of different dimension sizes as well as experiences of such dimensions.

- Drew: a bubble diagram showing a relationship between spatial features and various functions for a house.

The Blue Mountains site for the proposed weekender was a place where TG had lived for several years. So this particular building site raised strong feelings. She sifted through her expeniences and memories to make a short list of striking environmental characteristics to shape her design:

\section{Australian bush - gum trees with} elangated leaves - scents of eucalypts.

Australian wildlife - birds.

Climate - cloudless, deep blue summer skies - misty, focory winters sometimes snow - frosty momings.
TG thought about where a building might be situated to take advantage of these site aspects and her own experiences of the mountains. She drew a simple sketch of an idea for a building which curved around a sheltered courtyard. One side overhung the site's sloping decline so that the rooms there would be in amongst the bush treetops and receive the morning sun.

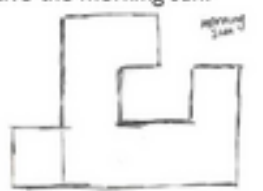

Subsequently and soon afterwards, she explored possible building shapes by changing one protruding side to a hexagon-like shape. Each side of this shape then looked out onto a view with a different focus: the courtyard, the cliffs. the treetops, the mist and fog. The other side of the building was extended so that there would be a corridor of bush between the two wings and to further shelter the lightly treed courtyard.

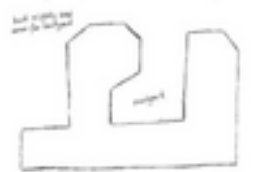

Figure 1: Week 1: Introducing the Subject Architectural Design: Design Basics 
Lecture: The lecturer used the first half of his paper 'Certain Universalities: How buildings come to be the way they are' (Harfield, 2002) which described the characteristics of buildings (form, materials, structure, artefact, function(s). space, location in time and place) and explored the infuences shaping the development of buildings. To end, the lecturer put forward three particular views about designing which he questioned, revealing that these views were problematic for him: design is a problem-solving activity: the brief represents an unmediated specification of the problem; and, the brief lies 'outside' the designer and 'leads' the designer to a solution.

\section{Studio:}

$1.30-1.45$ The tutor talked about issues pertaining to interviewing clients.

1.45 - 2.30 Discussion about the spatial and functional analyses that students had produced during the week and students also reported to the class (with various tutor prodding) the size and spatial requirements of common objects.

2.30 - 3.30 Students met with their client who was a writer. The client presented the design brief for her weekender, giving insights into her lifestyle, intentions, hopes, requirements and how she wanted to use the weekender with her husband as a place for writing and for entertaining creative friends. Then the class interviewed the client to glean further information.

$3.30-4.15$ When the client left, students reported back to the tutor and briefed him. The tutor analysed the client brief by asking students various questions and eliciting what might be 'missing' information.

4.15-4.30 The tutor ended the session by introducing the student tasks for Week 3: a new spatial and functional analyses based on the actual client brief and to produce three ideas based on the client's brief (one to be hand drawn only. one to be developed only using physical modelling and one to be written only.

Developing ideas: As required. TG prepared the following three design ideas to present to the class and tutor at the next studio session in Week 3 :
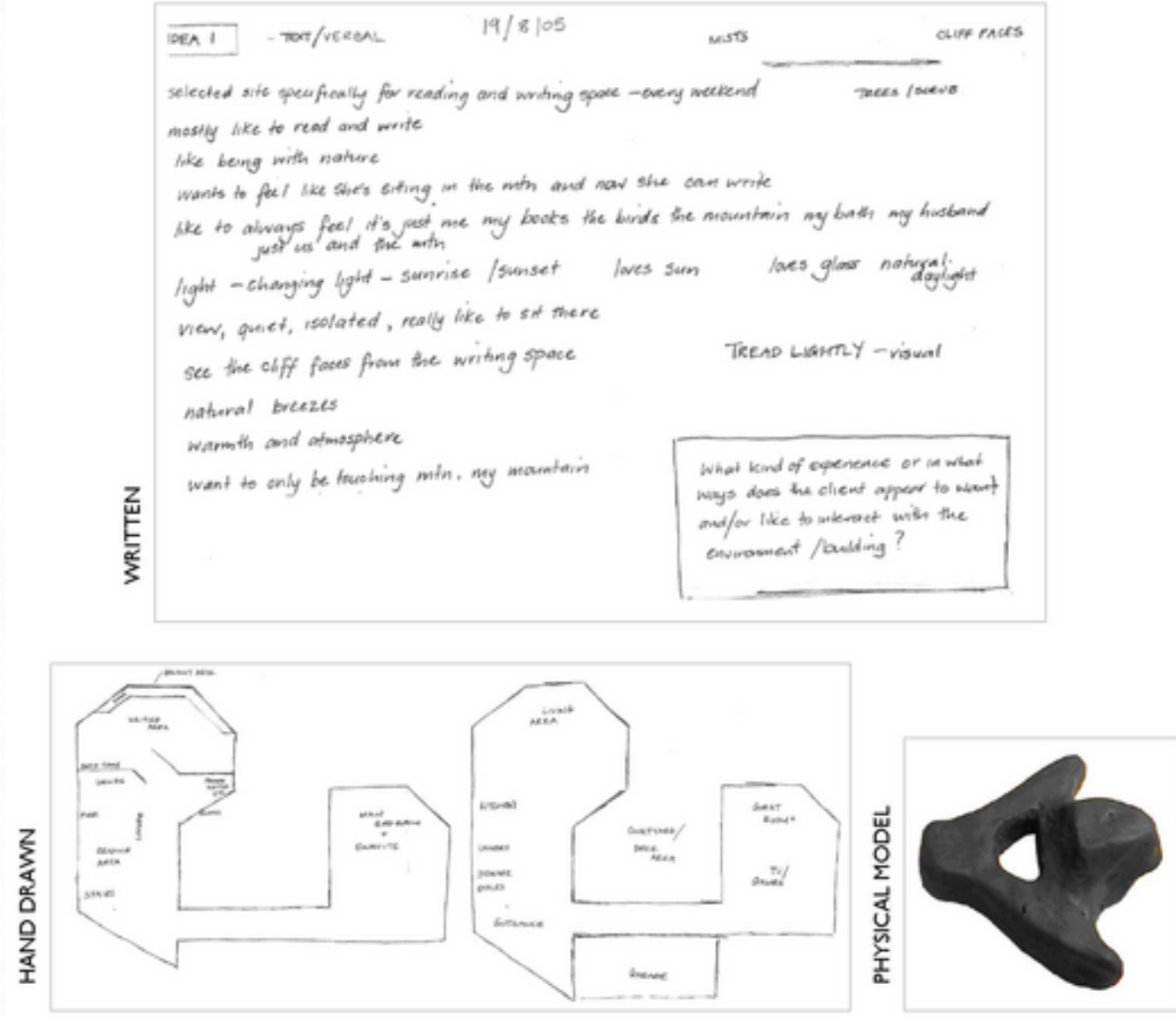

19 Aug 2005

Figure 2: Week 2: Meeting the Client and Starting Work on a Design Brief 
Lecture: Using the findings from his own research paper entitled 'Off the Top of their Heads' (Harfeld, 1997), the lecturer described first year students' perceptions of architectural design, and in particular the first four dimensions: ideas, process, requirements and purpose' (p. 34).

Studio:

$1.30-3.30$ Each student presented their three ideas to the tutor and class ( 6 minutes/student). The tutor provided feedback on these ideas in a range of ways, and in consultation with students he suggested one idea for rejection: this idea would not go on to be developed further in this project. All students were able to see and hear all the ideas that their peers had generated, the ones which were culed at this point and the comments the tutor made to assist students in designing the building. In this context the tutor also described which aspects of students' ideas were particularly salient for him, along with recommendations for how students might proceed with their designing. Figure 4 details the tutor's feedback on TG's three initial ideas during this studio session.

$3.30-4.00$ The students as a group then had another opportunity to interview the client in order to gather additional information or seek clanification. During this time, the tutor acted as a client in one of the other studio class groups. $4.00-4.30$ On his return, the tutor was briefed by students on additional or clarified information gleaned during the client interview.

The tutor ended the session by asking the students to take the two selected ideas forward, making a model, drawing and verbal description of each.

Developing ideas: In the third week, TG:

- Recognised: that modelling enabled fluidity of ideas.

- Observed: it 'helped me to think about other ideas, shifts, whilst the fingers were just moving'.

- Asked: What are the constraints of working with a plan in the initial phase?

- Noted: tutor's distinction between concept, idea, and plan, and his questions - What is going to allow me to make decisions about this building? A concept is an idea that gives structure to what you're thinking about. It allows you to make decisions. A concept is that decision that allows other decisions:

- Asked: How did other students develop a concept? - then model, sketch and describe it? - Sought: examples from the video and audio recording in the studio session.

- Asked: What is the relationship between students' ideas and my own?

- Asked: Concept is in relation to form?

- Noted: that perhaps in his feedback to students, the tutor had distilled a good approach to take and think about in designing for a client/environment.

- Listed: what these taked about principles in early designing might be.

TG tried to extend the client's desire to feel as if she was outside when she was inside and inside when she was outside. She explored the interplay between outside and inside in the two ideas selected by the tutor for development in the previous week. whilst thinking about his feedback of the principle of a gathering, a form of arms. In the first shape, the hexagon of the wing was repeated in the negative space of the courtyard and from the entrance one could see across the courtyard to the mountains. Perhaps an area could be excavated as a 'sleep out' or entertaining area beneath the protruding hexagon and below ground level. In the second idea, the inside garden was enclosed and curved to imitate the outside walls and glazed so that from the entrance one could look straight through bush and garden, through rooms and out to the other side of the valley.
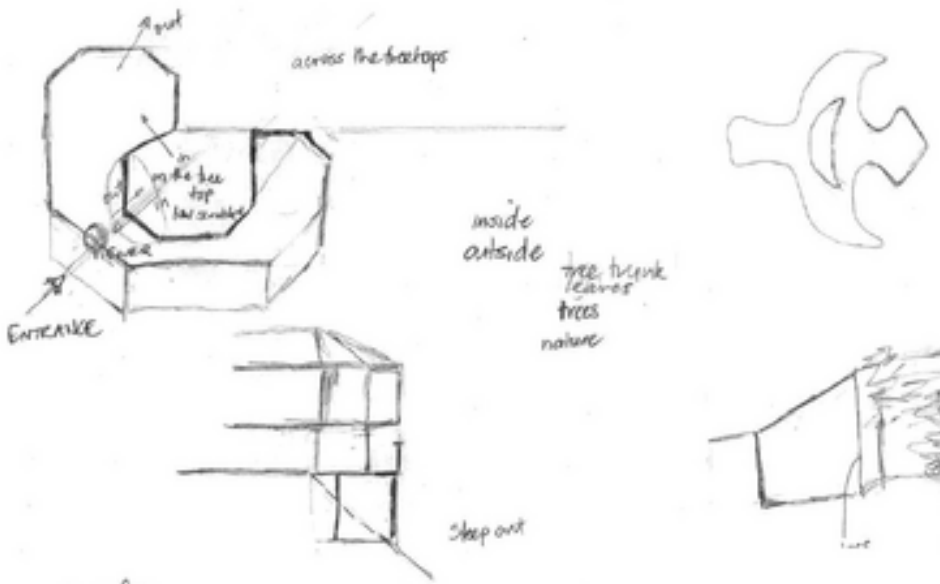

sewcingng for

The conapt

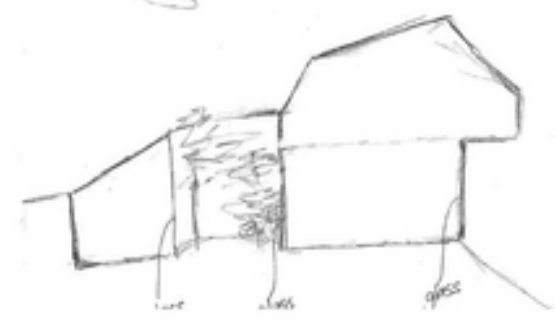

26 Aug 2005

Figure 3: Week 3: Presenting and Receiving Feedback on Initial Design Ideas 
TG's first design idea as a written description: Giving criteria for what the client wanted in her interaction with the environment.

Well I think your description - if you were to imagine everyone had to pass their piece of writing one person to the right, then for some people they would have a lot to work with in terms of an actual idea. So it says - 'it's a great big triangle building' - ok you can draw that. With that one [TG's description] it would be much more difficult because what it says is we're soll with a set of client descriptors that could be made into a number of things. Chad's is a bit the same in terms of it gives you a vision but if you then said. 'Can you draw what Chad's vision was' the answer would be 'no", because you'd say, 'hmmm I don't know what's he's thinking'

The tutor made similar comments to other students' work' how what was put forward was not yet a tangible form

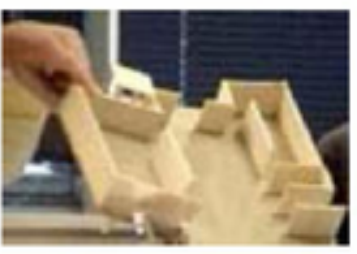

[A student's model to left] I can see each room. If you were to make each room out of cardboard we could put it together as a jgsaw puzzle. Forget the jigsaw puzzle. What is your vision of the picture that would be created by this? ... So what do you see when you see either the model or the drawing? What's this final form, do you think, in your mind?

[Another student's description] The last part of it sounded like a list of requirements... Now have you got something in mind for that writing? Or is it really just a list of client requirements in your mind? Can you see it?

TG's second design idea as a hand drawing: Introducing the drawing or diagram by walking through the location of different rooms and how these rooms were related.

If you were to simplify this to a diagram, because that's essentially what these are, what's the diagram of that? ... Tanja's got a whole lot of things in terms of where the bookcases are, where particular things may be. But essentially none of that is of any great importance at the moment other than she's got a particular idea that this is going to be either like a shallow $U$ that wraps around and contains an internal space, or a set of arms that kind of gather you around. Now, where things 80 , what the form's like, that's already moving a long way towards, to forcing it into a certain form. There's already a straight corridor, there's already something on one comer ... which she may not want to keep. And yet the general principle behind it is simply: as we approach from the street. and then we face and then we have something that gathers us around. In the same way that you had two large blocks or three dropping down the hill, the putty for this one is really just this kind of, this u. So we ve got a very different sensation from something that is cascading down and looking out. This one is kind of, it's not inward looking, because it's still very much looking to the north and it gathers around and that fits with your description. So for the moment I'm quite happy with just the hind of diagram because many of those things youll just throw away. You won't want to cut out the corridor. If you stick to the general idea then that howsoever this turns out, it can be the most complex of shapes or the most simplest of shapes, the general principle you've got for that one is a gathering around, a sheltering in the middle, looking outwards.

In his feedbock to students, the tutor made other comments relating to principles and how they drive the design ideas:

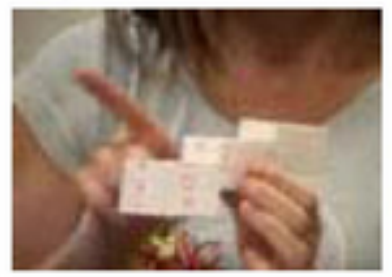

[A student's coscoding model, to left] When we saw the three elements tumbling down the hill, for me, that's a concept because every time you make a decision, that will inform the decision ... So this kind of constrains your ideas but it's a useful constraint because it allows you to keep saying 'does that fit with what I have in mind?'

[Student's idea with two cubes that contain particular functions] Yours with the two. You can change them from squares to triangles to circles. Anything you Ike. But the basic principle is there will be this one that contains these. There wll be that one that contains those. Theyll be separate and then l've got to do some connecting". So that for me is the difference between having a strong concept that allows you to test your own ideas.

TG's third design idea as a physical model: Showing the small plasticine model.

From a simple diagrammatic point of view, we ive got you wouldn't describe it as a donut but it's a solid shape with a hole in the middle. But this is again, now there's again those three fingers, coming back to that. So somewhere, something that the client said has got you both into this point that says we need a differentiation. But it's a nice little model in terms of it doesn't commit to too much, but it says 'Alright here we are. It's going to be like this, it's going to have a hole in the middle'. Again you'll have curvature. Again it's that same kind of arm gesture in a way, but very different, and then this rising up.

An example of a similar idea that another student designed into their model.

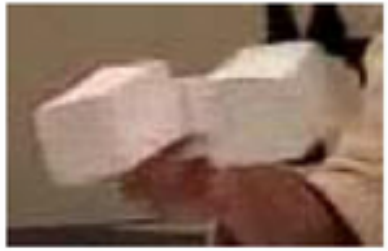

[Student describes their model] These fingers sort of sit into the hill, the hill still comes up between them .... and sort of separate functions for each finger, but it sits in with the hill so once you look out the ends there's the trees, so you're in with the mountain.

[Tutor question] So where does the two come from?

[Student's design rationale] The client wants two separate functions - one for private and one for entertainment but they can be expanded into other fingers that combine the same uses but are still separate from each other.

[Tutor comment] lt's got the same kind of gesture of gathering something in the middle.

Tutor's selection of two of TG's ideas for further development in this studio project.

So for Tanja's l'd take the model and I'd take the drawing and l'd just take the writing and say the writing is going to inform both of those. but it's not like a piece of writing that says 'a big triangle'. Whereas both these [the second and third ideas] they've got strong forms: I think the model is stronger than the drawing only because the model commits you to an idea without committing you yet to a whole set of more detailed propositions. Where the tendency is for the pencil, because it's easier, you start putting all the details in where you don't yet need the details. So take the model and the drawing and just lay over the top those things about nature and breeze and space and light because theyl impact into both. There's a big difference between the two: one says this is open and it gathers around but it's all open, this one [drown idea]. This one [model idea] goes further, it encloses completely and so there's a big difference between what happens here and what happens there. And that's what you should exploit, those differences.

Figure 4: Week 3: Tutor's Feedback on TG's Three Ideas 
Lecture: In continuing to give the second part of his talk. from 'Off the Top of their Heads' (Harfield, 1997) the lecturer reported to the students on the last four dimensions of design and his overall findings from this study. He also used part of this lecture to give advice on presenting design ideas professionally. Students were required to make a presentation the following week to their client, in much the same way asked of architects in their practice.

\section{Studio:}

1.30 - 4.30 The students discussed and showed their tutor and peers the ways in which they had progressed their two selected ideas for the building through modelling, sketching and verbal explorations and the tutor assisted students in the development of these two ideas. In his feedback, the tutor also probed and provoked the students to articulate what they were designing and why.

Figure 6 details the tutor's feedback on one student's work (Olle) as well as one of TG's design ideas. The tutor ended by discussing the tasks for the forthcoming week which entailed each student working up two design proposals to present to their client and completing the first assessment task, ready for submission.

ASSESSMENT \#I INITIAL DESIGN IDEAS - 15\% (assessed by Client)

- At the end of the meeting with the client each student is to submit to the client two (2) design proposals, each comprising appropriate hand drawings, written explanation, and photographs of any models (not models themselves: models may be presented to client at meeting).

- Work should be presented in A3 format. Submit only photocopies of drawings etc, not originals. Make sure your name \& student number is on every sheet number each page. With the exception of the site plan $(1: 200)$ any scaled drawings should be $1: 100$.

- At the session in Week $S$ the client will offer a brief crit of each idea presented during the session, and will select one idea for further development. This is the idea you will work on during the week.

- In addition, the client will return all submitted work in Week 6 with a more detailed written critique of each proposal submitted.

Developing ideas: After the studio session in the fourth week, TG

Asked: What is form? 's it 3D shope?

- Questioned: Hove I only been thinking in 2D? Is that why modelling might be a really good medium for working up initiol ideas?

- Looked: for a shape in art books.

- Pondered: how that shape might become a form and how a form has more dimensions.

- Appropriated: a shape from Malevich's The Mower.

- Questioned: How would an understanding of the biological basis of Art (eg work of Ramachandran (2003), Zeki (1999)) shape a particular kind of building? Might an element of intrigue, warmth curiosity be built into a building?

- Borrowed: the book 'Architectural drawing: A Visual Compendium of Types and Methods' (Yee, 2003).

TG reworked the model, imagining curves with a dome-shaped roof slanting down the x-shaped building. A ' $V$ ' and inverted ' $V$ : one embracing the bush and looking out to the views and the other as gathering arms that welcome visitors into the building. and in the centre where these two v's intersected was a semi-circle, an open-air deck and scented native garden. She thought about how this form could be described using evocative words to arouse curiosity and intrigue. When it rains, water cascades down from the second level over the void and down the courtyard windows. Perhaps this will need a way of shading during midday/summeriwhile away? TG thought about the movement of water down the roof - like being under a stream - and what it might feel like to be looking up from under such a stream. She then considered what the dimensions of the building might be for these kinds of experiences.

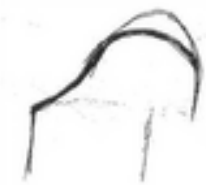

1 don't know of certain thing ave posisie structurally r aloo what moteviak then micht be miln we astivt we wir when to build

Figure 7 shows the two proposals that TG prepared to present to the client in Week 5 and to submit as Assessment Task \#1.
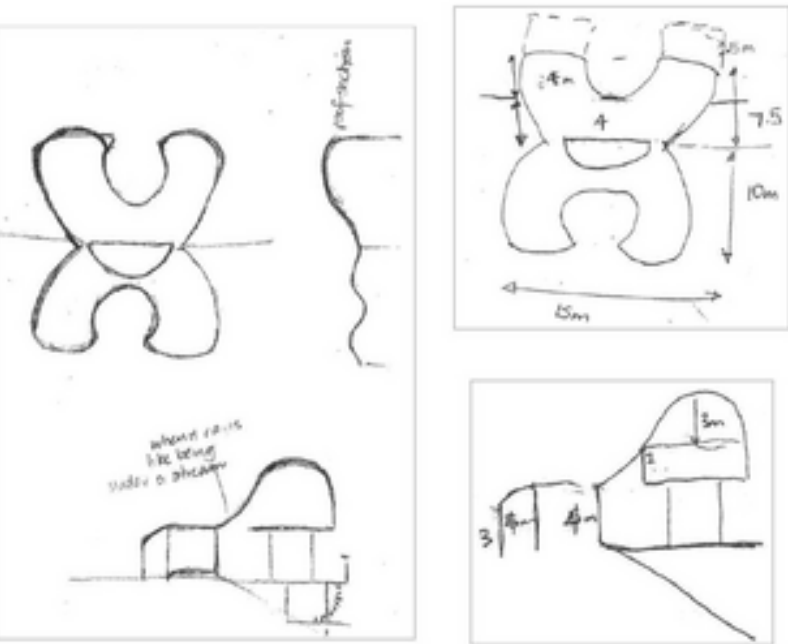

Figure 5: Week 4: Progressing Two Selected Design Ideas 
Another student's design idea (Olle)

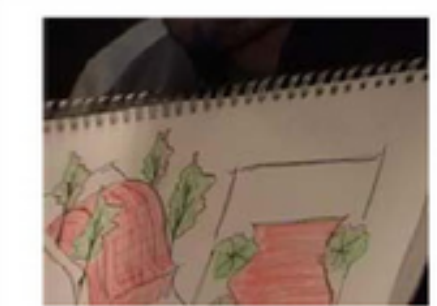

In Week 3 Olle had described one of his design ideas, the drawing as follows:

It's about the mist and the fog in the valleys.

And I wanted it to be a light structure that moves with the site

and maybe doesn't have to look like this.

but just like you can move around with the nature.'

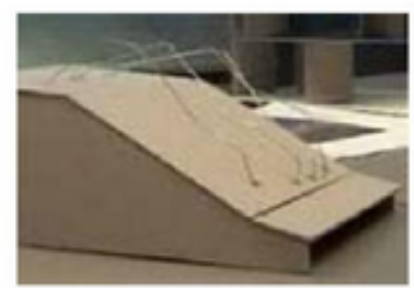

Now in Week 4, he worked up a model of that idea using four wire lines bent as they travelled down the slope of the site.

The tutor oskect So what was shown there is, these are going to be structural elements?

Olle: Yes probably, it's not the final yet.

Tutor: Last week it started off as a rather simple shape, but the curvature was rather weak because it was just the roof that was folded ... now this has gone a long way. So we ve now got quite a ngorous way of thinking about it. At the moment it's basically rectangular on plan although certain points become important. He started with simply four kinds of lines so that they have at the moment quite consistent starting points. But then rather than being all the same, which it was in the original flowing curve, each one of these has then a different kind of profile and therefore the roof is going to be a direct outcome, the form is going to be a direct outcome of what he's chosen there.

Ok it's dropping down the site, we can see. I'm assuming the way you have drawn it means the building is going north/south and the steps are going east/west.

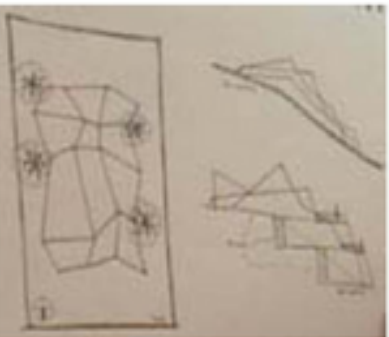

Tutor. Another thing we've got on the plan that we don't see on the model is it starts out as a kind of rectangle but it's actually a four-by-three grid. Now you can imagine, start with [holds up a rectangular piece of poper] divide that four by three and where the grid points are that's where the structure is, that's where things change. Now all that's happened in that is that oniginal rectangle's deformed. It's still four by three, but there's going to be, however many there are, 20 individual node points from which things happen. So we're really joining the top left hand corner, the southeast corner, we join to the next one and Ole can put those wherever he likes. But the logic is telling us. wheresoever these points are, that will establish the form. I can move them, I can do whatever I like with them. And if he's good on computer, he can put all the [coordinates] into the computer and just grab one point and drag and the rest of it would have moved with it... He could have taken any one point and just pulled it and everything would have moved like a net.

So at the moment we don't yet know quite what this is going to look like. We can now see a section. Weive got endless possiblities. Well not quite endless possibilities because he's already told us - there's going to be 20 points.

The tutor then illustrates particular consequences of using this 20-node co-ordinate language for roof and ground planning and for envisaging uses and experiences of bulding space, highlighting two particular odvantoges of mediating design in this woy it allows both complete and systematic exploration of possibilities.

TG's first design idea in Week 4: a solid shape with a hole in the middle and an arm gesture

Tutor's feedback comments In the drawing we don't get the impression of curves. There is a clash between the language of the model and that of the drawing. This may just be a lack of skill in representing the form and idea.

There is a prominence of the top storey in the model which is a natural outgrowth of the shape. This is missing in the drawing.

Girculation questions: Entry and then one could go right or left. Courtyard - do you walk around the courtyard or through it to get to the next area? Curves could be used as a way of getting to the northerly spaces.

The size and dimensions of the rooms and their functions will correct the curves.

Is it a symmetrical or asymmetrical form? Depending on which it is wil change the nature of the building.

With the shape, will the planning layout fit so nicely or will there be squeezing a bit to fit?

Figure 6: Week 4: Tutor's Feedback on a Classmate's (Olle’s) and TG's Design Ideas 

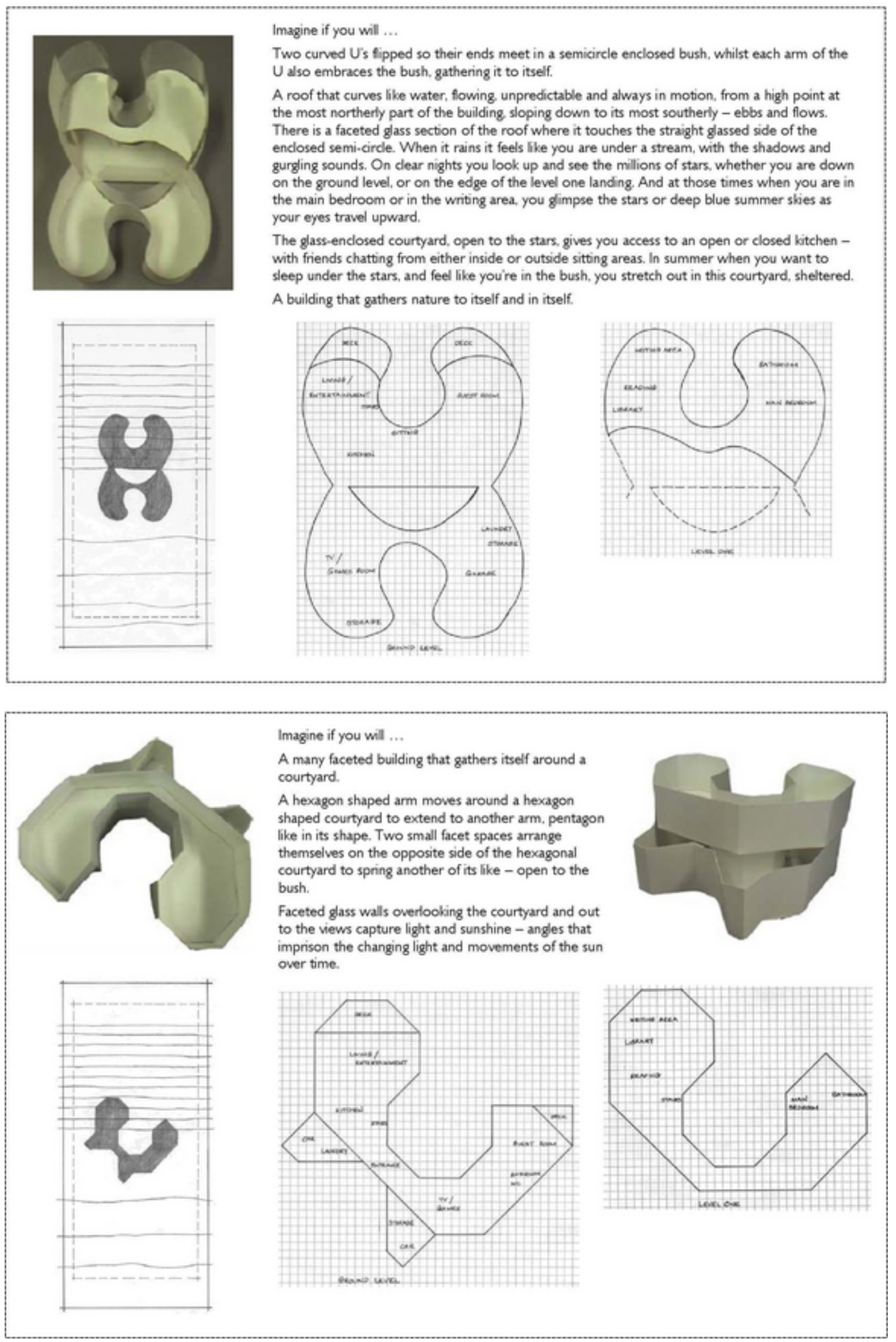

Figure 7: Week 4: Completing Assessment Task \#1 
In Week Three, in their studio class, TG and her classmates faced their first direct feedback on their set of three initial ideas. Here, the tutor extracted some of the patterns or principles that underpinned particular students' ideas: principles such as 'a cube within a cube' and 'three elements tumbling down the hill'. Using the terms 'concept' and 'principle' interchangeably in his feedback to students, the tutor suggested that TG's two concepts might be:

1. 'a shallow $U$ that wraps around and contains an internal space, or a set of arms that kind of gathers you around ... the general principle you've got for that one is a gathering around, a sheltering in the middle, looking outwards' and

2. 'a solid shape with a hole in the middle ... again it's the same kind of arm gesture in a way, but very different.'

This feedback provoked TG to rethink what might be the principle or concept that was guiding the development of each of her forms or ideas for the building and the ways in which these could be represented and communicated to others. In retrospect, the architectural basis of these different principles may have been implicit in the feedback to the class. However, at the time TG tried hard to recognise which architectural ideas were being built into her and her fellow students' designing. When the tutor provided each student with feedback on their ideas, at critical points he also emphasised the worth of distilling these general principles in generating form. According to him, such extraction of principles:

- generates 'rules' or guides which the designer is in control of;

- supports an openness to possibilities but also acts as a constraint;

- allows testing of subsequent ideas for fit;

- enables the designer to go beyond the client's explicit brief;

- seems to make sense immediately of the design itself;

- enables a view of the big picture; and

- makes explicit the reasoning behind why a design is powerful.

Once the principles underpinning students' different design ideas were made explicit, it was up to each student to use them to develop their idea (now a concept) and in the process, to test the worth of their particular principles. For TG, this proved to be a struggle after the studio in Week Three. When she confronted the feedback in Week Four, both to the class and to her undeveloped design ideas, she began to recognise the architectural design basis that could influence the developing form: for example, the circulation and movement within the form, the dimensions and size of the internal areas in relation to what was going to take place within those areas, the visual and spatial experiences a person might have inside the form. She struggled to find a means to explore the ways in which a particular set of principles might shape the form of her building.

Clearly, TG's concept of design seemed to be developing dynamically. In the early weeks, design looked to her like a very exploratory process of drawing from personal experience, of seeking out and collecting visual ideas, and playing with materials. This view of designing sits comfortably with Ferguson's view (1993) of design as a visual, nonverbal process wherein a 'visual language' emerges from the mind's eye:

The mind's eye, the locus of our images of remembered reality and imagined contrivance, is an organ of incredible capacity and subtlety. Collecting and interpreting much more than the information that enters through the optical eyes, the mind's eye is the organ in which a lifetime of sensory information - visual, tactile, muscular, visceral, aural, olfactory, and gustatory - is stored, interconnected, and interrelated (p. 42).

For TG, as for Ferguson, design was 'a contingent process, subject to unforeseen complications and influences as the design develops' (p. 37).

Then, in Week Three, her view of design began to shift, when students' design ideas received their first feedback. It appeared to take on more of what Schön terms 'a conversation with the materials of a situation' (1991, p. 78), involving reflection-in-action where the 'situation's back-talk' refines possibilities and choices. As initial design ideas were chosen or culled by the tutor's feedback, design began to echo Vincenti's view, too: as a process of variation and selection, where artefacts are made to 'work' in the world around them and the real world acts on the design (Vincenti, 2000). In hindsight, the tutor's probing of how these students' ideas might work (for example, for the client, for the site, for the context, structurally) appeared a deliberate teaching strategy, to assist students to understand Vincenti's 'real-world selection': interactions occurred within real-world constraints (such as laws of nature) as tests of design success, influencing subsequent design processes.

In Week Four, the tutor and students began to use particular media to supply incubators (after Papert, 1980, p. 120) in which ideas could be formed up and progressed, and predictions could be made. By that point, design seemed to be taking on the dynamic properties of an evolutionary process as Ziman et al (2000) characterise it: 'to design ... [means to] 'artificially select' far more promising variants than would turn up by chance' (p. 315). Consequently, it has a historical and hence an epigenetic character: 
The range of feasible variants at a given moment is not limited solely by present circumstances, such as the materials and tools currently available: it is also conditioned by memories of past circumstances, such as unsuccessful configurations and ideas, and by mental images of future circumstances, such as of a hypothetical device in action (Ziman et al, 2000, p. 315).

When TG searched for a means by which to know and represent her ideas, as well as to understand what possibilities lay within such ideas, she used a simple moulding material for giving form to them. This enabled her to progress these ideas to a certain point, and in so doing, to recognise the potency of her choice of medium, as Leunig does:

The tactile aspect of claymation is a lovely thing when the hands are touching and moving things and there's material, you know, when you engage in material which is not abstract it's solid. You can hold it in your hands. Then you're relieved of the tension of your mind, you know. It's not just running around in your mind. It's running down into your hands and back into your mind. So it's a different loop you're in. And this. The hands make accidents that the mind, I don't know, different sorts of accidents. Interesting things happen (Leunig, 2002).

At the start of Week Four, though, the development of TG's design ideas faltered. However, being privy to what another student (Olle) designed and how the tutor responded allowed TG to glimpse the extraordinary power of a particular medium for making explicit and progressing design ideas. In Olle's case, it was possible to conceive of his design in the language of mathematics: by imagining an irregular and dynamic co-ordinate geometry within which a continuum of roof designs existed and limiting cases could be expressed. Only when this system was explicit could Olle's design be fully understood - as one of a continuous, infinite array of possibilities, each with particular dimensions, and consequently, character. TG had had some direct experience of the power of her own modelling medium, but she had also clearly struggled with its limits. Here, in the vicarious experience of Olle's design and the tutor's feedback on it, TG could gain much deeper insight into how conceptual progression can be successfully mediated. The experience made strong sense of the tutor's guiding feedback to students in Week Three: 'You've got to use modelling, not make a model of something. You've got to use materials to see what ideas are coming out of your mind'. Now, in Week Four, this approach had become much sharper for TG and design had started to look like what Papert describes as a love affair with another mathematical technology - gears:

Gears, serving as models, carried many otherwise abstract ideas into my head (p. xviii-xix)

... The gear can be used to illustrate many powerful "advanced" mathematical ideas, such as groups or relative motion. But it does more than this. As well as connecting with the formal knowledge of mathematics, it also connects with the "body knowledge" ... You can be the gear, you can understand how it turns by projecting yourself into its place and turning with it. It is this double relationship - both abstract and sensory - that gives the gear the power to carry powerful mathematics into the mind (1980, p. xx).

Just as gears had carried mathematical ideas into Papert's mind, TG was beginning to recognise the power of particular technologies (be they modelling materials such as clay or geometrical languages such as co-ordinate systems) to support the processes of architectural designing.

\section{Conclusion}

Clearly, the developmental dynamic that is apparent in the growth of TG's ideas about architectural designing in these first four weeks took place within a carefully planned amalgam of opportunities to learn. Teaching academics provoked her generation and testing of design ideas, alongside her classmates, with an authentic project brief for a building and supported students' refinement of their design concepts with real-world studio experience including critical response. Whilst we do not pretend to characterise these first four weeks' growth as full-blown expertise, we argue here that we can see in TG's evolving ideas and approaches, clear signs that within the experience of this subject, given her active commitment to learning from it, there are the beginnings of the growth of a particular, highly individualistic kind of design expertise. Such expertise appears to grow in idiosyncratic ways, as the product of a confluence of circumstances, fitted to a learner's aspirations. In TG's struggle to learn to design, we can recognise a case in point of the development that Plotkin (1994) described holistically (as epigenesis) in the following words:

... each individual is, in a real sense, created anew, the unique outcome of an immensely complex series of interactions between the different parts ... of that individual; and also between its genes, its developing parts and its environment. Epigenesis is the word used to describe this complicated, integrated, dynamic 
and probabilistic process of development ( $\mathrm{p}$. 122).

As such, these early findings sit comfortably with our research group's generative theory of learning (after Plotkin, 1994 and Edelman, 1992) in which learning occurs through a Darwinian (selectionist) heuristic: as learners generate and test ideas on their value, keeping those that survive their tests (Schaverien and Cosgrove, 1999, 2000).

Of course, TG's learning to design did not stop here in Week Four. Nine more weeks of classes followed, on a similar educational pattern; and analysis of the data from these last weeks is still underway, and will no doubt shed further light on the preliminary findings reported here. Furthermore, this study represents only the first of a two-part doctoral investigation, the second study of which interrogates the worth of architectural design ideas grown here for their particular worth in educational design. This doctoral thesis attempts to make a significant critical contribution to the understanding and use of a concept and/or process (that of design) which, appropriated by educators, has been at best overused and at worst maligned. It squarely addressed the question: Can Education be conceived, at core, as a designing discipline? If so, in what respects, and if not, why not?
Obviously, the selective reporting within this paper of a rich and complex study has its difficulties. Much data has been omitted, risking a partial story. For now, however, if this first paper can provoke imaginative and critical discussion of designing at the interface of architecture and education, we will be well pleased.

\section{Acknowledgment}

We wish to acknowledge Steve Harfield for the privilege of learning about architectural design from his teaching and leading of the teaching team of the subject Architectural Design: Design Basics at the University of Technology, Sydney. We are grateful for the generosity and openness of students and tutors in this subject who made TG feel part of their learning community and from whom she also learned much about designing. It was only through the Faculty of Design, Architecture and Building's recognition of the value of this doctoral investigation and their and our shared aspirations to understand design education much more deeply that it was able to proceed. Finally, we were able to present an early version of this paper at the International Conference on Design Principles and Practices through the generous support of Professor Shirley Alexander and funding provided from the UTS: Institute for Interactive Media and Learning.

\section{References}

Atman, C., Chimka, J., Bursic, K. \& Nachtmann, H. (1999). A comparison of freshman and senior engineering design processes. Design Studies, 20(2), 131-152.

Chi, M. (2006). Two Approaches to the Study of Experts' Characteristics. In K. Anders Ericsson, N. Charness, P. Feltovich \& R. Hoffman (Eds.), The Cambridge Handbook of Expertise and Expert Performance. (pp. 21-30). New York: Cambridge University Press.

Cross, N. (2004). Expertise in design: an overview. Design Studies, 25(5), 427-441.

Edelman, G. (1992). Bright Air, Brilliant Fire: On the matter of mind. London: Penguin Books.

Eteläpelto, A. (2000). Contextual and strategic knowledge in the acquisition of design expertise. Learning and Instruction, 10, 113-136.

Feltovich, P., Prietula, M. \& Anders Ericsson, K. (2006). Studies of Expertise from Psychological Perspectives. In K. Anders Ericsson, N. Charness, P. Feltovich \& R. Hoffman (Eds.), The Cambridge Handbook of Expertise and Expert Performance. (pp. 41-67). New York: Cambridge University Press.

Ferguson, E. (1993). Engineering and the Mind's Eye. Cambridge, Mass: The MIT Press.

Harfield, S. (1997). Off the Top of Their Heads: The nature and processes of architectural design as perceived by new intake students. Form/Work, 1, 34-48.

Harfield, S. (2002). How buildings come to be the way they are. In R. Best \& G. DeValence (Eds.), Building in Value: Design and Construction. (pp. 17-32). Oxford, UK: Butterworth Heinemann.

Kavakli, M. \& Gero, J. (2002). The Structure of Concurrent Cognitive Actions: a case study on novice and expert designers. Design Studies, 23(1), 25-40.

Lancy, D. (1993). Qualitative Research in Education: An Introduction to the Major Traditions. New York: Longman.

Leunig. M. (2002). Leunig Animated. DVD.

Mayr, E. (1998). This is Biology: The Science of the Living World. Cambridge, MA: Belknap Press.

Merriam, S. (1998). Qualitative Research and Case Study Applications in Education. San Francisco: Jossey Bass.

Papert, S. (1980). Mindstorms: Children, Computers, and Powerful Ideas. New York: Basic Books.

Plotkin, H. (1994). The Nature of Knowledge. London: Allen Lane, The Penguin Press.

Ramachandran, V. (2003). The Artful Brain. In V. Ramachandran, The Emerging Mind. (pp. 46-69). London: Profile Books. Ross, P. (2006). The Expert Mind. Scientific American, August 2006, 46-53.

Schaverien, L. \& Cosgrove, M. (1999). A biological basis for generative learning in technology-and-science: Part I - A theory of learning. International Journal of Science Education, 21(12), 1223-1235. 
Schaverien, L. \& Cosgrove, M. (2000). A biological basis for generative learning in technology-and-science: Part II - Implications for technology-and-science education. International Journal of Science Education, 22(1), 13-35.

Schön, D. A. (1991). Reflective practitioner: How professionals think in action. Aldershot England: Arena.

Seitamaa-Hakkarainen, P. \& Hakkaraninen, K. (2001). Composition and Construction in Experts' and Novices' Weaving Design. Design Studies, 22(1), 47-66.

Stake, R. (1995). The Art of Case Study Research. Thousand Oaks, Ca: Sage Publications.

Vincenti, W. (2000). Real-world variation-selection in the evolution of technological form: historical examples. In J. Ziman (Ed.), Technological Innovation as an Evolutionary Process. (pp. 174-189). Cambridge, UK: Cambridge University Press.

Yee, R. (2003). Architectural drawing: A visual compendium of types and methods. Hoboken, N.J.: J. Wiley.

Zeki, S. (1999). Inner Vision: An Exploration of Art and the Brain. New York: Oxford University Press.

Ziman, J. et al. (2000). An end-word: By all contributors. In J. Ziman (Ed.), Technological Innovation as an Evolutionary Process. (pp. 312-316). Cambridge, UK: Cambridge University Press.

\section{About the Authors}

Tanja Golja

Tanja Golja is a doctoral student in the Faculty of Education, researching the fruitfulness for Education of the concept of design. As part of her responsibility as an academic developer within the Institute for Interactive Media and Learning, Tanja works closely with academic staff in the Faculty of Design, Architecture and Building, collaboratively seeking to enhance the Faculty's design and successful provision of rich learning opportunities for students within the designing disciplines. As a graduate of the foundation cohort of the Master's degree in e-learning, Tanja takes a special interest in online environments and currently oversees the university's design and use of its customised Blackboard e-learning environment.

\section{Dr. Lynette Schaverien}

Associate Professor Schaverien is an active researcher in science and technology education, with a special interest in understanding the design of theoretically sound e-learning environments in a range of disciplines. In recent years, she has led two sizeable and successful Australian Research Council projects in which students and teachers respectively have designed acclaimed and radically innovative e-learning environments in which others can engage with scientific, technological and educational questions of high interest to them. In both these projects, designing and learning to design are of key interest at two levels: in participants' shaping of the environments themselves and in researchers' enactment of a research process to nurture and understand it. She has also led the design, development and teaching of a market-leading suite of postgraduate e-learning courses, in collaboration with her university's Institute for Interactive Media and Learning. 